in from her home to set matters right. This brought me some unpopularity.

The basic trouble was deeper, as I found. It was not widely appreciated that the whistle was actuated by the nitrous oxide, and nobody ever thought of turning it off to stop the noise. I took the lever off again, hid it, and attached a notice to the alarm saying, "To stop whistle turn off nitrous oxide." I publicized these arrangements to everyone I thought they concerned. I even composed a small brochure about the Boyle machine, including a description of these precautions, and distributed it to the British Oxygen Company. All, one would have thought, would now be well.

But yet another hazard became apparent. Some months later the oxygen ran out and once again the whistle was dumb. The lever had been replaced and carefully turned off The hospital had a maintenance contract, and the engineer on his routine visit had noted the absence of a lever on the tap and as was his contractual duty, replaced it. I warned the theatre staff to inform him of our local arrangements on his next visit, and for some months after that we had a reliable oxygen alarm. My regular association with that theatre ceased a year or two ago. On a recent visit there I was not entirely surprised to find that a bright new lever has appeared on the alarm, which is now firmly and tidily turned off.

This danger will never be eradicated until the makers omit the tap altogether and replace it by an engraved notice stating that the whistle is actuated by the nitrous oxide, which may be turned off to stop it.-I am, etc.,

\section{Wallasey, Cheshire}

R. L. WYNNE

\section{Relative Risks of Obesity and Smoking}

SIR,-In an earlier paper on obesity and smoking habits ${ }^{1}$ we showed that men who had never smoked were considerably heavier than smokers and that ex-smokers who gave up smoking for more than eight years approached the body weight of the neversmoked group. Because of the inverse relationship between obesity and smoking it is of interest to assess the relative risks of these two hazards in coronary heart disease, and this is especially of importance for exsmokers who are attempting to give up the smoking habit, possibly at the cost of putting on weight. While evidence on the relative risks of obesity and smoking is still lacking, in the meantime we are able to present some results on complaints of heart disease in that population. We hope eventually to produce evidence on the relative risks of obesity and smoking from a mortality study of our steelworks population.

In our survey of steelworkers at Port Talbot and Ebbw Vale ${ }^{2}$ a shorter version of the Medical Research Council questionnaire on respiratory symptoms was used with the following question added: Have you ever suffered from heart trouble (coronary, rheumatic, congenital, or any other)? The percentages of affirmative answers by age and smoking habit are shown in the table. Within each of the three age groups after 35 , about $2 \%$ more heart trouble was reported among the ex-smokers and smokers than in the never-smoked group. Among the

\begin{tabular}{|c|c|c|c|c|}
\hline \multirow{2}{*}{$\underset{\text { Habit }}{\text { Smoking }}$} & \multicolumn{4}{|c|}{ Age Group (years) } \\
\hline & $25-34$ & $35-44$ & $45-54$ & $55-64$ \\
\hline $\begin{array}{l}\text { Never smoked } \\
\text { Ex-smoker .. } \\
\text { Smoker } \quad .\end{array}$ & $\begin{array}{c}2.3 \\
(926) \\
1.5 \\
(614) \\
2.3 \\
(2,271)\end{array}$ & $\begin{array}{c}1 \cdot 1 \\
(721) \\
3 \cdot 1 \\
(1,080) \\
3 \cdot 1 \\
(3,431)\end{array}$ & $\begin{array}{c}2.5 \\
(527) \\
5.4 \\
(856) \\
4 \cdot 1 \\
(3,061)\end{array}$ & $\begin{array}{c}6 \cdot 1 \\
(264) \\
8 \cdot 6 \\
(580) \\
8 \cdot 6 \\
(2,015)\end{array}$ \\
\hline
\end{tabular}

Figures in parentheses represent numbers of cases.

ex-smokers and smokers there was a steady increase in the percentage of affirmative answers with age. But the trend with age was lacking in the never-smoked group until 55 years.

The three smoking groups were greatly different in their mean body weights. The never-smoked group was heavier than smokers within each of the four age groups. The difference increased with age from $6 \mathrm{lb}$ $(2.7 \mathrm{~kg})$ at age $25-34$ to $16 \mathrm{lb} 7.3 \mathrm{~kg})$ at age 55-64, and the ex-smokers, though lighter than the never-smoked group, were much heavier than smokers (table III, Khosla and Lowe ${ }^{1}$ ). Though the smokers were considerably lighter than the never-smoked group they (the smokers) reported (if anything) a trend towards a higher percentage of heart trouble at age 35 and over.

Fifty per cent of total male deaths in the age range 45-64 years in the United Kingdom are attributable to lung cancer, chronic bronchitis, and coronary heart disease. ${ }^{3}$ Lung cancer and chronic bronchitis are directly related to smoking, and they account for $20 \%$ of the total deaths. Considered together, it appears prudent from the epidemiological point of view to give up smoking even at the risk of putting on weight. The suggestion that the overall reduced risk in ex-smokers more than offsets possible increases in mortality due to a weight gain ${ }^{3}$ is a reasonable hypothesis for preventive action.

Further research is in progress in our departments.-We are, etc.,

Department of Medical Statistics

T. KHOSLA

Department of Social and Occupational Medicine, Welsh National School of Medicine,

1 Khosla, T., and Lowe, C. R., British Medical Fournal, i971, 4, 10

2 Lowe, C. R., et al., British fournal of Preventive and Social Medicine, 1968, 22, 1 .

Royal College of Physicians, Smoking and Healt
Now. London, Pitman Medical Books, 1971.

\section{Suppuration in Rheumatoid Arthritis}

SIR,-Suppurative polyarthritis is an established complication of rheumatoid arthritis and we have had 11 patients with this condition under our care in the past nine years. In five there was an associated pneumonia and in four of these the responsible organism was Streptococcus pneumoniae. It is with these four patients that this letter is concerned.

One of these four patients, a woman aged 62 who had had rheumatoid arthritis for 14 years, presented desperately ill, very breathless, and cyanosed, giving a four-day history of increasing breathlessness. A chest $x$-ray showed consolidation of her left lower lobe, and thick pus was aspirated from both knee joints, though there was nothing beyond the presence of effusions into these joints to suggest suppuration. Strep. pneumcniae was isolated on blood culture, but treatment proved unavailing and she died within hours of admission.
Postmortem examination confirmed a clinical diagnosis of lobar pneumonia with septic arthritis. The remaining three patients, all men aged between 52 and 69 who gave a history of rheumatoid arthritis of four to eight years duration, presented with an exacerbation of their joint symptoms. Two admitted to recent chest trouble but in none were symptoms or signs of chest disease very obvious and the underlying pneumonia could easily have been missed on clinical examination.

Even before the advent of antibiotics, overt suppurative arthritis complicating pneumococcal pneumonia was rare and the figure of 1 in 800 cases was suggested by Herrick. ${ }^{1}$ Now the incidence is likely to be less. Clearly patients with rheumatoid arthritis are especially susceptible to this complication and we are writing this letter to emphasize the importance of aspirating any suspect joints, especially those recently swollen, in patients with rheumatoid arthritis who develop pneumonia, and of $x$-raying the chest routinely in patients with suppurative polyarthritis.-We are, etc.,

\section{N. T. GOODCHILD} E. D. SEVER J. P. TOBY

General Hospital,

Northampton

1 Herrick, J. B., American fournal of the Medical
Sciences, 1902, 124, 12 .

\section{Bronchodilatation Induced by Methoxyflurane}

SIR,-Methoxyflurane (Penthrane) is a selfadministered analgesic used in childbirth. We have investigated the bronchoactivity of methoxyflurane in seven adults with normal ventilatory indices by means of a whole body plethysmograph. It is usual practice to express resistance of the airways as specific airways conductance, which is conductance divided by lung volume. After control values had been obtained the subject remained seated in the plethysmograph and inhaled from a Cyprane Cardiff inhaler through the standard face mask. The inhaler delivers methoxyflurane at a fixed concentration of $0.35 \% \mathrm{v} / \mathrm{v}$. The exhalate was voided externally to avoid contamination of the plethysmograph. Breathing was at tidal volume for $1 \frac{1}{2}$ minutes, following which the specific conductance was remeasured immediately.

Six subjects showed a rise in specific conductance (range $7 \cdot 2 \%$ to $33.6 \%$; mean $20.3 \%)$. Bronchodilatation also occurred in the seventh subject, but this was overridden by a larger change in lung volume.

Thus we feel that consideration should be given to favouring this analgesic for women presenting with airways obstruction or with a history of asthma.-We are, etc.,

\section{R. B. Douglas} S. M. FORSEY

T.U.C. Centenary Institute,

London School of Hygiene and

Tropical Medicine,
London W.C.1

\section{Neonatal Jaundice and Maternal Oxytocin Infusion}

SIR,-We read with interest the article by Dr. D. P. Davies and others (1 September, p. 476) on neonatal jaundice and maternal oxytocin infusion. We have recently looked for a similar association in a group of neonates. Bilirubin levels were measured in 
cord blood and from venous samples on days 4 and 7 in infants born after surgical induction of labour and intravenous oxytocin infusion. A control group of neonates was also studied. Haemolytic disease was excluded in all infants by appropriate investigation. The mean birth weight, gestational age, incidence of operative delivery, and breast-feeding on discharge was similar in both groups. The results are summarized in the table.

\begin{tabular}{|c|c|c|c|}
\hline & \multicolumn{3}{|c|}{$\begin{array}{c}\text { Mean Biliburin in } \mathrm{mg} / 100 \mathrm{ml} \\
\quad \pm \text { S.E.M. }\end{array}$} \\
\hline & Cord & Day 4 & Day 7 \\
\hline $\begin{array}{l}\text { Oxytocin Group } \\
\mathrm{N}=13\end{array}$ & $\begin{array}{r}2.308 \\
+0.233\end{array}$ & $\begin{aligned} & 5 \cdot 285 \\
+ & 9.94\end{aligned}$ & $\begin{array}{r}3.69 \\
+0.91\end{array}$ \\
\hline $\begin{array}{l}\text { Control Group } \\
\mathrm{N}=14\end{array}$ & $\begin{array}{r}2.507 \\
+0.277\end{array}$ & $\begin{aligned} & 5 \cdot 35 \\
+ & 0.8\end{aligned}$ & $\begin{array}{ll} & 3.50 \\
+ & 0.560\end{array}$ \\
\hline
\end{tabular}

The mean total bilirubin in cord blood was lower in neonates delivered after oxytocin-induced labours, but this difference was not statistically significant. No difference between mean bilirubin levels on days 4 and 7 was apparent. Furthermore, we could find no correlation between the total dose of oxytocin infused and neonatal bilirubin levels.

Though the results of our study are in conflict with the authors' findings, we would endorse their view that any possible association between maternal oxytocin infusion and neonatal jaundice should be viewed in the proper perspective, and a small rise in bilirubin level is unlikely to be of importance in a healthy term baby of normal birth weight.-We are, etc.,

D. C. Davidson J. A. FORD W. MCINTOSH

Departments of Medical Paediatrics and

Biochemistry,

Glasgow

\section{Congenital Syphilitic Nephropathy in an} Adopted Infant

SIR,-In view of the rising incidence of syphilis, the current interest in congenital syphilitic nephropathy, and recent moves to change screening procedures for adopted children, we would like to report an instructive case.

A 16-week-old illegitimate boy awaiting adoption was admitted to this hospital for investigation of haematuria and proteinurea. His natural mother was apparently well, the pregnancy and delivery were normal, and a maternal Wassermann reaction at eight months' gestation was reportedly negative. Neonatal examination had been normal, but subsequently there were feeding difficulties. At the age of 13 weeks he developed proteinuria and haematuria following an upper respiratory infection.

Examination revealed hepatosplenomegaly and moderately enlarged kidneys but no oedema, lymphadenopathy, or snuffles. Hypoalbuminaemia, heavy but highly selective proteinuria, raised plasma IgM levels, and femoral subperiosteal new bone formation were present. Serum cardiolipin W.R., Reiter complement fixation test, Treponema pallidum immobilization test, serum V.D.R.L. slide test, and IgG and IgM fluorescent treponemal antibody tests were all positive.

A diagnosis of congenital syphilitic nephritis was made and the patient was successfully treated with a three-week course of procaine penicillin. The natural mother was traced and found to have no clinical evidence of syphilis but weakly positive serology. She was given a course of penicillin reatment. The prospective adoptive parents serology was negative, and in spite of this illness they have subsequently adopted the child.

In this case maternal exposure to infection ceased after the child was conceived and no antibiotic was administered during pregnancy. At eight months' gestation maternal serology must have been positive and the negative W.R. was either an error or reflected an insufficiently sensitive test. For routine screening the V.D.R.L. slide test would seem preferable, and in those at particular risk repeating it in the last trimester, with a subsequent test for cord-blood IgM fuorescent treponemal antibody, would seem to be indicated.

In the light of this case we wish to emphasize the need to consider syphilis in infantile nephritis or nephrosis, even with a negative prenatal history, and feel that the medicosocial implications of failure to achieve antenatal diagnosis in a subsequently adopted child justifies careful reapioraisal of syphilitic screening procedures in pregnancy. -We are, etc.

Hospital for Sick Chiluren,

M. J. DilloN Great Ormond Street, London W.C.1

\section{Infantile Herpes Zoster}

SIR,-In reply to Dr. G. D. W. McKendrick and S. C. Raychoudhury (11 August, p. 352), we regret omitting any reference to thei paper. ${ }^{1}$ This was not intended to mislead, but in the space available in a short annotation it was not possible to refer to all the relevant literature.

The special importance of our case of herpes zoster in a young child was not only the exposure to varicella in utero but also the virological confirmation of the diagnosis which is absent from most similar published reports. In stating the two hypotheses for the pathogenesis of herpes zoster we merely wished to indicate that both are considered possible by some. $.^{3}-\mathrm{We}$ are, etc.,

I. K. LEWKONIA

University College Hospital,
London W.C.1

A. A. JACKSON

McKendrick, G. D. W., and Raychoudhury, S. C., Scandinavian fournal of Infectious Diseases, $1972,4,23$.

Berlin, B. S., and Campbell, T., fournal of the

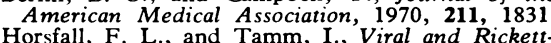
Horsfall, F. L., and Tamm, I., Viral and Rickett-
sial Infections of Man, 4th ed. p. 918 . London
Pitman, 1965 .

\section{Muscle Cramps during Maintenance Haemodialysis}

SIR,-We welcome the paper by Dr. G. R. D Catto and others (18 August, p. 389) on the treatment of muscle cramps in haemodialysed patients with Slow Sodium tablets. The neglected problem of dialysis cramps is now beginning to receive the attention it deserves

With reference to their data, however, we should like to point out that a reduction in the mean frequency of cramps from 54.7 to $40.7 \%$, though statistically significant, is perhaps less significant to the patients, as $40 \%$ is still considerably troublesome. It is also perhaps misleading to express the difference of $14 \%$ as a percentage of the $54.7 \%$ and refer to this as a "reduction of $26 \%$." Most people would be inclined to call a change from 54.7 to $40.7 \%$ a reduction of $14 \%$. The same criticism apolies to their description of the change in severity from 5.4 to 3.8 arbitrary units as a "reduction of $30 \%$." Moreover, judgement of the severity of the cramps, when related to a 10-point scale, must have been difficult for the patients. Within so wide a scale a change from 5.4 to 3.8 units must have been small in terms of the relief afforded.

Notwithstanding the marginal nature of the improvement, Dr. Catto and his colleagues claim that the administration of up to 14 tablets of Slow Sodium on each dialysis day is a better way of controlling cramps than "an increased sodium concentration in the dialysate for all patients." We on the other hand, recommend ${ }^{1}$ the use of isonatric dialysis (dialysate sodium concentration of $145 \mathrm{mmol} / \mathrm{l}$ ), combined with appropriate ultrafiltration. Isonatric dialysis with controlled ultrafiltration brought about a reduction in the incidence of cramps from $55 \%$ to $13 \%$ in our patients, ${ }^{2}$ and the current incidence is $<15 \%$ (extreme range per patient nil to $35 \%$ ). Thus, the frequency of cramps is noticeably greater using the conventional dialysis, even with Slow Sodium, than when using controlled isonatric ultrafiltration.

Isonatric dialysis is compatible with complete and satisfactory control of blood pressure. ${ }^{3}$ In fact, hypertension has not been a problem, either longterm or short-term, despite what might seem to some as more adverse clinical conditions in Dundee -namely, only 16 to 18 hours of total dialysis time per patient per week, divided into two sessions. The inter-dialysis weight gain of 3 to $5 \mathrm{~kg}$ is partially a consequence of the restricted dialysis time available. Contrary to the belief of Dr. Catto and his colleagues our patients do not complain of thirst; they revert to near normal, old-established patterns of fluid intake. Medical injunctions to alter eating and drinking habits may work in the short term but are rarely effective for long.

Dr. Catto and his colleagues seem to value the ability to "tailor" the number of tablets to each individual patient's needs, but the practicalities of tailoring the number to individual needs (presumably retrospectively) could be difficult in a busy dialysis unit. The prospect of swallowing up to 14 tablets each dialysis seems daunting to us. Multiple pill-swallowing is also surely more prone to error than the use of a standardized dialysate composition which, with a "physiological" concentration of sodium, has proved in our experience to be suitable for all patients. Certainly it seems contradictory to be deliberately removing sodium from the patient with one hand (dialysis with low sodium concentrations) while feeding him sodium with the other. It would have been interesting to know the plasma sodium concentrations of their patients and how often it was monitored. Even 24 hours after dialysis using a dialysate sodium concentration of $135 \mathrm{mmol} / 1$., plasma sodium concentrations can be as low as 131 to $133 \mathrm{mmol} / \mathrm{l}^{4}$

We continue to believe that, in the course of haemodialysis treatment, the removal of accumulated dietary sodium is most easily accomplished by the net transfer of the "surplus" extracellular fluid during controlled isonatric ultrafiltration." This single process can be closely monitored during dialysis through the parallel change in body weight. A concomitant of this straightforward technique is a marked reduction in the prevalence of dialysis cramps. The conventional approach with hyponatric dialysate (sodium approximately $130 \mathrm{mmol} / \mathrm{l}$.) involves the unmonitored dialytic transfer of 